\title{
Hybrid T-I-D and Fuzzy Logic Based SVC Controller for Transient Stability Enhancement
}

\author{
Poonam Singhal*, Sakshi Sharma** \\ *(Associate Professor, Department of Electrical Engineering, YMCA University of Science \& Technology, \\ Faridabad-121006 \\ ** (M.tech Student, Department of Electrical Engineering, YMCA University of Science \& Technology, \\ Faridabad-121006
}

\section{ABSTRACT}

This paper presents a new approach to solve the transient stability problem. The conventional PI based SVC controller has simple functioning and is economical in operation but has sluggish performance with non-linear characteristics. so, in order to circumvent this problem, fuzzy based T-I-D controller has been designed to improve the transient stability of 2 machine 3 bus power system using MATLAB/SIMULINK software.

Keywords: FACTS; PI Controller; SVC; Fuzzy Logic Controller; T-I-D Controller.

\section{INTRODUCTION}

In modern power systems, system stability issues are of tremendous significance. In order to operate a system in a safe, reliable state, it is imperative to maintain its stability. The stable parallel operation of $\mathrm{AC}$ generators and the power system stability concepts were proposed by the experts for the very first time in the early decades of the 20th century. However, those ideas and concepts presented in the past are not applicable for the modern power systems. This has subsequently been reflected in the definition of Stability, realizing this, the power system stability definition and classification from a modern point of view has been systematically introduced here. Also, there exists a close relationship between reliability, stability and security. Maintaining the stability of a system to ensure its reliability; a secure system is always a result of its reliable operations. Generally, power system blackouts begin with the loss of stability. Experts started to learn from these blackouts that in order to maintain power systems in a safe, reliable state, the power system operation should emphasize on the improvement of the system stability through various strategies. In summary, the term "stability" imparts as an important concept for the world's electric power generation, transmission and distribution systems. The operation of power systems cannot be conducted without considering it.

A definition of power system stability can be proposed: Power system stability refers to the ability that all the synchronous machines in a power system have to return to the previous equilibrium states, or move to new steady states, if there is a disturbance.

It is known that disturbances play a key role in triggering destabilization in the systems, and may cause big problems. Short circuits and sudden loss of power grid element may happen. The continuous variation of loads can also affect the operation and control of generators. Therefore, in practice, the stability of power systems experiences many disturbances every time, as the environment keeps varying. If the system is not properly designed or operated, a small disturbance may lead to a severe power outage. In such a scenario, FACTS devices render themselves as very important elements to the power system. The recent trends suggest that they are finding increasing emergence throughout the world.

\section{SVC DESCRIPTION}

In power transmission systems, the compensation of reactive power is important, especially in the cases of heavy loads. As large real power is transferred from power generation units to loads, the voltage drops in transmission lines leads to a poor voltage regulation in the transmission line at receiving end. Therefore, reactive power is needed in order to maintain the voltage level in the systems, as well as to ensure stability.

However, it is common that not enough reactive power is provided to power systems, especially at remote areas far from power plants. Sometimes, even adding the reactive compensation from the transmission line equivalent shunt capacitors may not be sufficient. Therefore, extra reactive power compensations are helpful if a power system operates in an overloaded conditions, or if the voltage level needs to be adjusted, SVCs provide appropriate solutions to these problems. SVCs were developed in 1960s. They are most commonly used FACTS devices, and reference defines SVC as a shunt-connected static VAR importer or exporter 
whose output VARs are adjusted to maintain bus voltage of the electrical power system within a specific range.

Since SVCs have been used in the power systems for several decades, the technologies have been improved, and SVCs have brought about many uses for power systems. As previously mentioned, SVCs enlarge the transmission capability by supporting the line voltage Moreover, when the power systems are in their steady states, SVCs mainly eliminate the system voltage variations, smooth the effects of continuous load changes, damp oscillations, and the reactive compensation function can also help to correct power factors to improve the power quality. Furthermore, for the transient process, if systems suffer from sudden large disturbances which lead to severe voltage drops, SVCs react immediately to provide a strong reactive power support, enhancing the system voltage stability and transient stability.

In the active control range, the Susceptance (Bsvc) and, hence, the reactive current is varied according to the voltage regulation slope characteristics shown in Fig. 2.

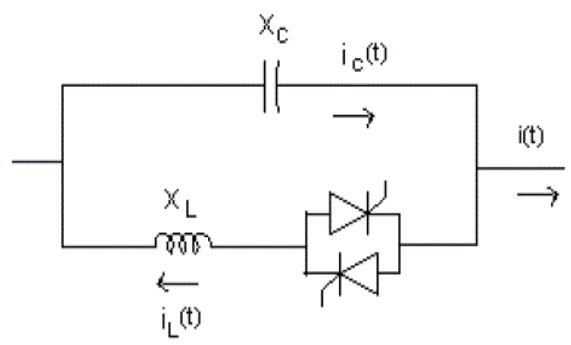

Fig.1 Basic Structure of SVC [4]

The slope is determined by the desired voltage regulation. Typically, it varies between $1-5 \%$. The SVC behaves like a shunt capacitor of maximum value (BCsvc) at the capacitive limit, and as fixed shunt reactor at minimum value (BLsvc) corresponding to the inductive limit. These limits are reached when there are large variations in the bus 15 voltage. The inductive limit is reached when the bus voltage exceeds the upper limit, whereas the capacitive limit is reached when it falls below the lower limit.

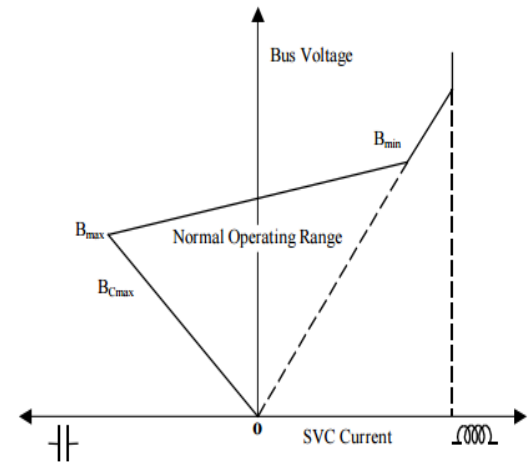

Fig.2 Svc Output Characteristics

The SVC can be represented by its shunt current injection model. The current injection( $\mathrm{I}_{\mathrm{SVC}}$ )into the bus, where the SVC is connected, can be written as,

$I_{S V C}=j B_{S V C}$

$B_{S V C}=B_{C}-B_{L}=\frac{1}{X_{C} X_{L}}\left\{X_{L}-\frac{X_{C}}{\pi}[2(\pi-\alpha)+\sin 2 \alpha]\right\}$

where, $X_{L}=\omega L, X_{C}=\frac{1}{\omega C}$

and , $B_{S V C}, \alpha, X_{C}, X_{L}$ are the reactive power injected into the bus due to svc can be expressed as, are the shunt susceptance, firing angle, inductive reactance and capacitive reactance of the SVC, respectively. $\omega=2 \pi f$, where $f$ is the frequency of the supply. The reactive power injected into the bus due to SVC can be expressed as,

$Q_{S V C}=B_{S V C} V^{2}$

where, $V$ is the voltage magnitude of the bus at which the $\mathrm{SVC}$ is connected.

\section{POWER SYSTEM MODEL}

A 2 machine 3 bus power system model in MATLAB/Simulink is used for the purpose of study. The power rating of machine 1 is 1000 MVA which is connected to load center with the help of a $700 \mathrm{~km}$ transmission line, operating at $500 \mathrm{KV}$. Load is of resistive type of $5000 \mathrm{MW}$, supplied by machine 2 of rating 5000MVA

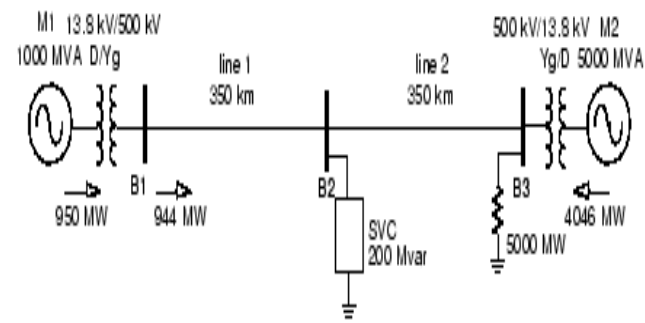

Fig.3. Single line diagram a 2 machine 3 bus system

The current and voltage at bus B2 is measured and the corresponding data is fed as input to the SVC controller. Now the role of SVC is to regulate the value of Voltage at the bus. The difference between the measured value of the voltage and the desired value of Susceptance (B p.u.) obtained as output from the voltage regulator. Subsequently, firing angle delay is given to the Thyristors of TCRs(Thyristor Controller Reactors) and TSCs(Thyristor Switched Capacitors).This mechanism can be illustrated with the help of figure. 4.The firing angle delay decides the nature of current injected by the SVC into the system. 


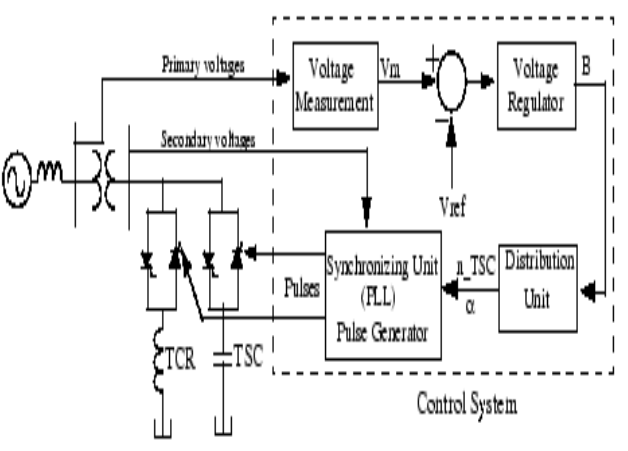

Fig.5. T-I-D Controller Application in SVC

\section{FUZZY LOGIC CONTROLLER}

Fuzzy set theory renders itself as an excellent means for representing uncertainty in the any data or unprecedented behavior of a system. It represents the human control processes and also employs experimental knowledge in adjusting the controller parameters.

FIS (Fuzzy Inference System) consists of the following components:

1. Input variables

2. Fuzzification through membership functions

3. Rule-base (if/then rules)

4. Defuzzification through membership functions

5. Output variables

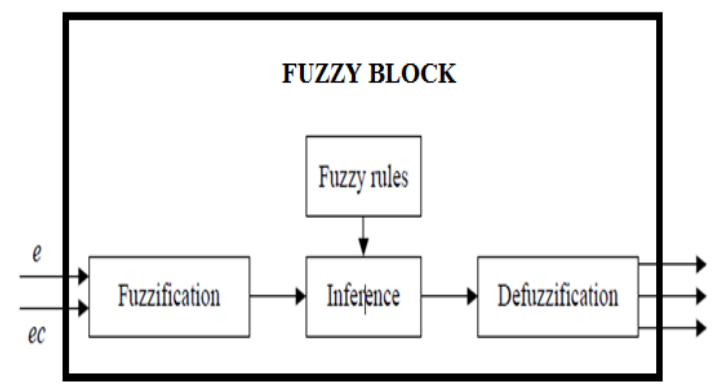

Fig.6. Fuzzy Logic Controller Block Diagram

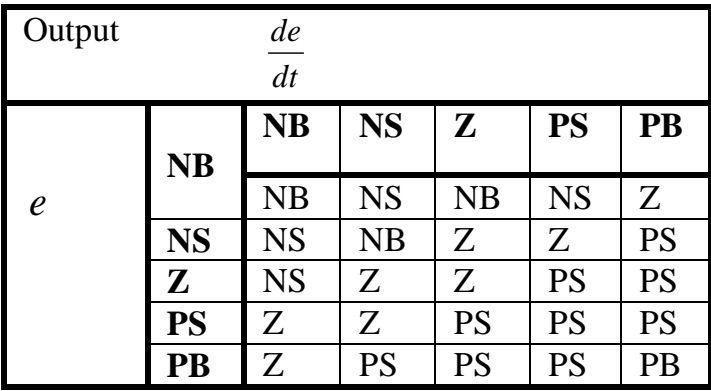

\section{i) Input Variables}

Typically a fuzzy controller has at least 2 inputs and one output. In this paper, the inputs to the fuzzy logic controller are the error in the voltage and change of error, while its output acts as the control signal.

Input1: $e=V_{\text {ref }}-V_{\text {meas }}-\left(B_{\text {svc }} V_{\text {meas }} X_{s}\right)$

Input2: $\frac{d e}{d t}=\frac{d\left(V_{\text {ref }}-\left(B_{S V C} V_{\text {meas }} X_{S}\right)\right.}{d t}$

\section{ii) Fuzzification}

Fuzzification is defined as a conversion of real input to fuzzy set values. For eg.

$\mathrm{NS}(\mathrm{x})=\{0$ if $\mathrm{X}<-1.0$ or $\mathrm{X}>0 ;\}$

$$
\begin{aligned}
& =(-0.5+X) / 0.1 \text { if } X>=-1.0 \text { and } X<-0.5 \\
& =(-X+0.5) / 0.1 \text { if } X>=-0.5 \text { and } X<0 \\
& =0 \text { if } X>0\}
\end{aligned}
$$

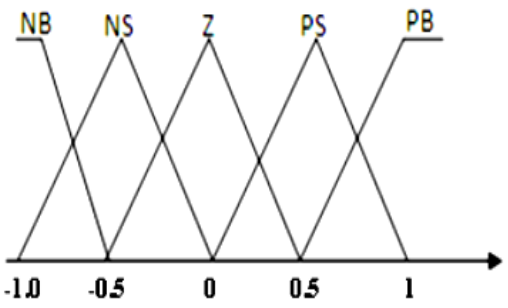

Fig.7. Input Membership Function

Different types of parameterized membership functions commonly used are:

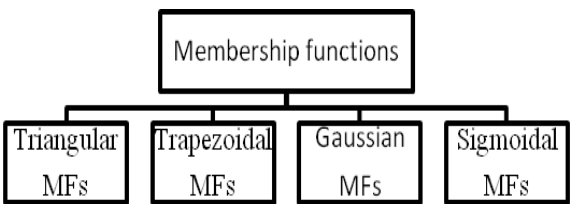

Fig.8. Types of membership functions

\section{iii) Rule Base}

The Rule Base is described as a "If Then" format wherein the 'If' side represents the condition and the 'Then' side represents conclusions.

Rule1:If error in voltage, $e$ is NB and the error change $\frac{d e}{d t}$ is NB then the output is NB.

Rule 2: If error in voltage, $e$ is $\mathrm{Z}$ and error change $\frac{d e}{d t}$ is $\mathrm{PB}$, then the output is PS.

Table.1 Fuzzy Inference Rules $\mathrm{NB}=$ Negative Big , NS=Negative Small, $\mathrm{Z}=$ Zero, $\mathrm{PS}=$ Positive Small, $\mathrm{PB}=$ Positive Big.

\section{iv) Defuzzification}


The objective of Defuzzification is to find one single crisp value which summarizes the fuzzy set. There are several mathematical techniques that are used to perform this.

a. Centroid Method,

b. Centre of Sums,

c. Weighted Average Method

d. Modified Center of Area

e. Mean of Maximum

f. Centre of Gravity

Centroid method is employed where the output will be calculated as

$O=\frac{\sum_{i=1}^{5}\left(b_{i} \int \mu_{i}\right)}{\int \mu_{i}}$

Where $\mu i$ symbolizes the membership function and $b i$ symbolizes the membership of member $i$ of output fuzzy set.

\section{SIMULATION RESULTS}

A three phase fault is created at bus 1 for a period of $0.1 \mathrm{~s}$. from 5 to 5.1 seconds. The designed controller has a precise control to make the system stable after the fault is cleared. During the fault when there is a dip in the bus voltage (high current), svc injects the reactive var into the transmission line where it is connected to regulate the voltage. The MATLAB/Simulink is given below: The Tilt Integral Derivative controller is a newly designed controller which has good performance and gives reliable results over PI based controller. Moreover, TID compensator has a good transient rejection ratio, simpler tuning, and a few effect on the closed loop system response. The first overshoot is reduced using T-I-D Controller. The deviations in Bus terminal voltage and speed of generator are also reduced.
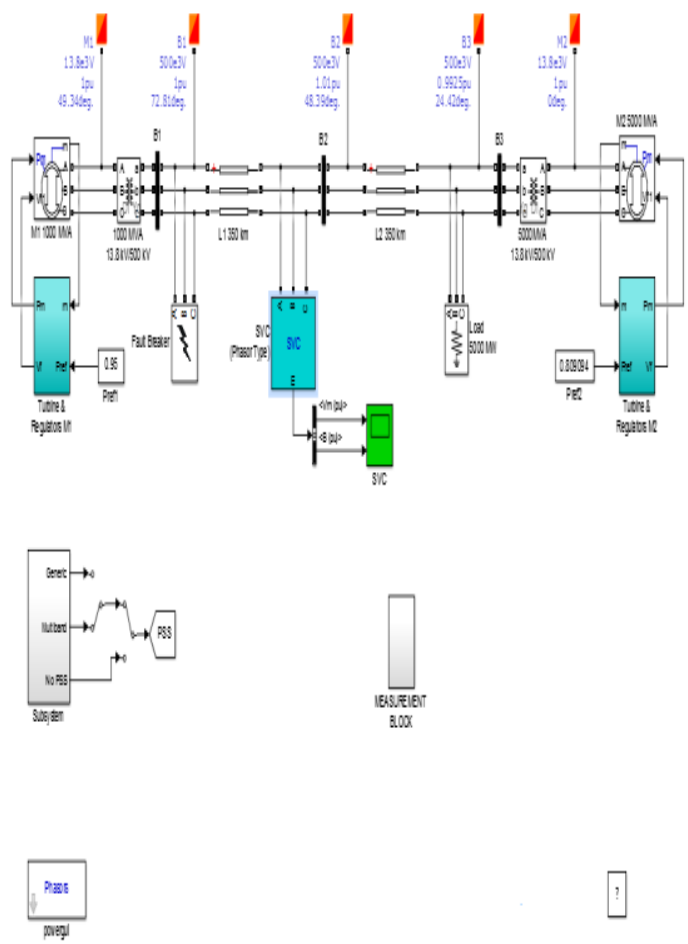

Fig.9. MATLAB/Simulink Model for system

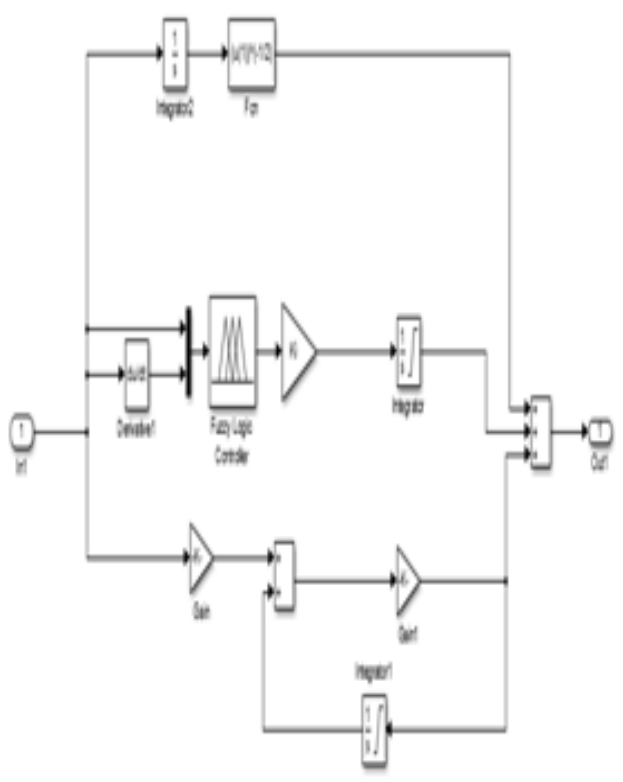

Fig.10. Hybrid TID-Fuzzy Logic Controller

Following Simulation Results are obtained using MATLAB/Simulink Software with the help of Power System ToolBox.

a) Terminal Voltage at bus 2: Time response of machine 1 Terminal Voltage at bus 2 


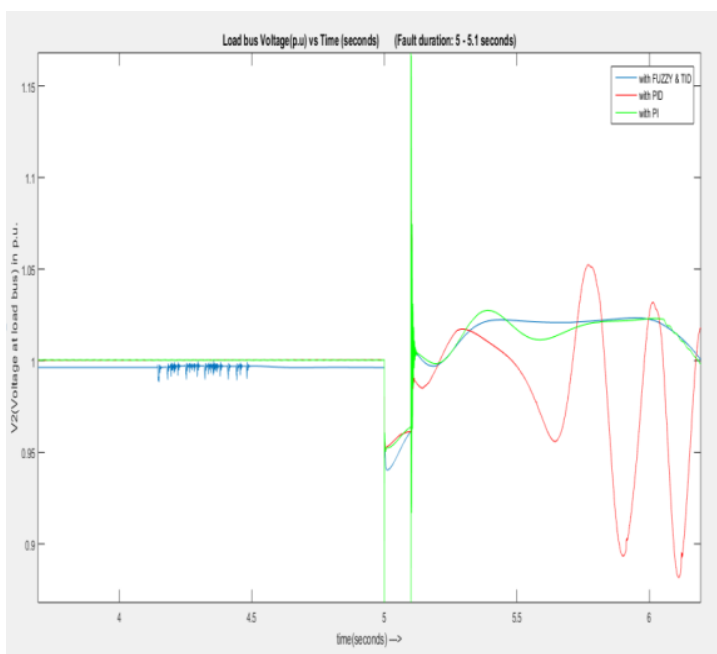

Fig.11. Terminal Voltage at bus 2(With Fuzzy Logic based T-I-D SVC Controller PI Controller, and Conventional PI SVC Controller)

b) Speed Deviation between Generator1 and Generator2: Below shows the Time Response simulation result of Rotor Speed Oscillations between Generator1 and Generator 2.

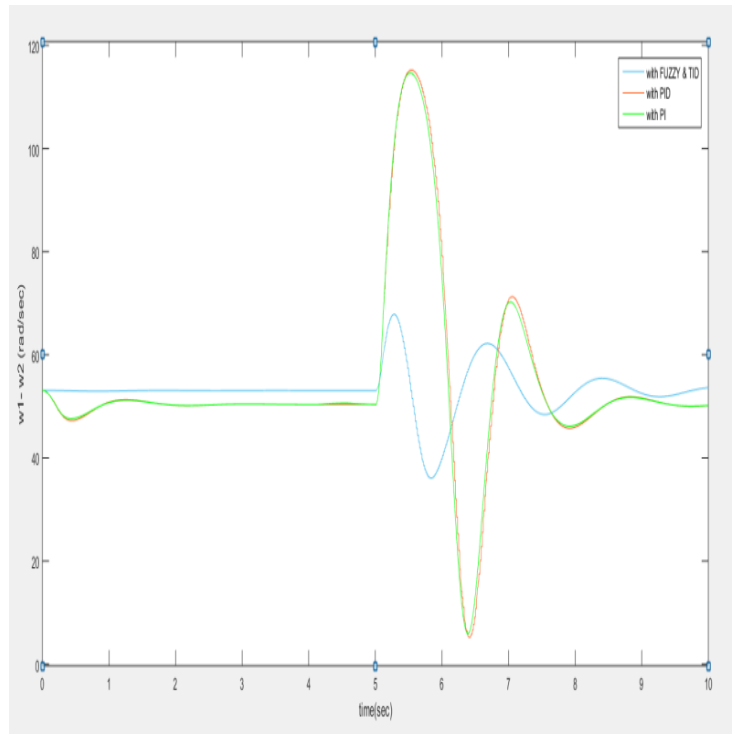

Fig.12. Speed deviation (w2 - w1) (With Fuzzy Logic based T-I-D SVC Controller PI Controller , and Conventional PI SVC Controller)

c)Rotor Angle deviation between Generator1 and Generator 2:

Time Response of Rotor Angle Oscillations

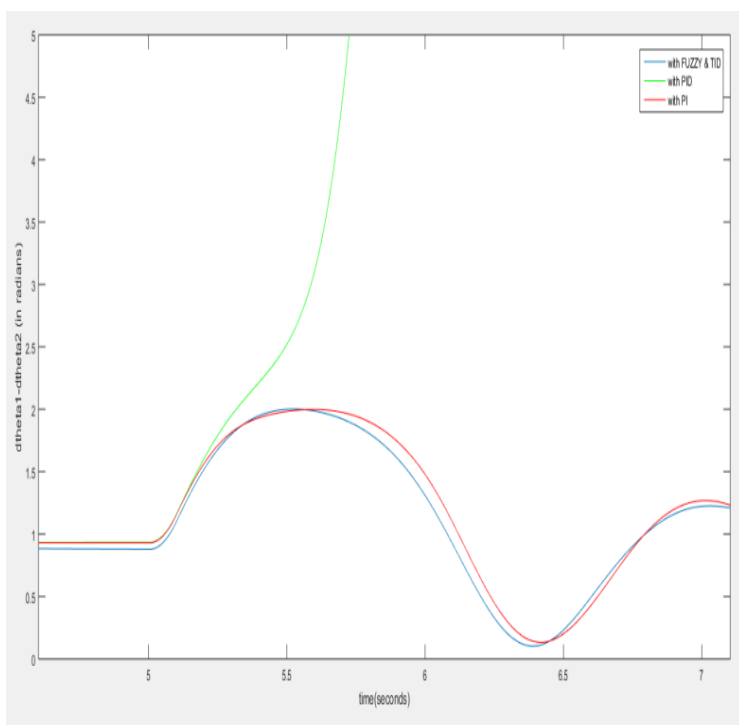

Fig.13. Rotor Angle deviation between Gen1 and Gen 2 (With Fuzzy Logic based T-I-D SVC Controller PI

Controller, and Conventional PI SVC Controller)

\section{CONCLUSION}

\section{i) Terminal Voltage at bus 2}

The first undershoot in Bus Voltage at Bus 2 using TID Controller is 0.945 p.u and that with PID and Conventional SVC Controller is 0.95p.u and 0.874 p.u. respectively. T-I-D SVC Controller is able to deal with non-linearity faster than PID Controller.

\section{ii) Speed Deviation between Generator1 and Generator2}

The speed deviation between Generator1 and Generator2 i.e (w2- w1) radian/seconds are reduced from 115 radian/seconds to 68 radians/seconds using TID SVC Controller.

\section{iii) Rotor Angle Difference between Generator1 and Generator2}

The rotor angle difference for PID Controller is not as desired and keeps on increasing. Out of PI Controller and TID Controller the latter has slightly better response.

\section{FUTURE SCOPE}

In this paper, hybrid T-I-D and Fuzzy Logic Based SVC Controller is tested on a 2 machine 3 bus SIMULINK model in MATLAB. It can be concluded that this controller improves the transient stability of the system by reducing the overshoot in voltage and by giving a faster response and smaller settling time than PI and PID Controllers. The performance of the designed controller is reliable and is quite stable. Further work will be done on improving the transient stability of SVC using Genetic Algorithm Technique to optimize the Gain Constants of T-I-D Controller.

\section{REFERENCES}


[1] Prabha Kundur, John Paserba, Vijay Vittal, Definition and Classification of Power System Stability IEEE/CIGRE Joint Task Force on Stability Terms and Definitions .IEEE Transactions On Power Systems, Vol. 19, No. 2, May 20041387

[2] Manogna, Smt. B.Lalitha. TransientStability Improvement in Transmission System using SVC with PI-Fuzzy Logic Hybrid Control. IOSR Journal of Electrical and Electronics Engineering (IOSR-JEEE) e-ISSN: 22781676,p-ISSN: 2320-3331, Volume 10,Issue 4 Ver. III (July - Aug. 2015), PP 114-121.

[3] Poonam Singhal, Parmod Kumar Madotra.Transient Stability Enhancement of a Multi Machine Power System Using SVC Controller. International Journal ofEmerging Trends \& Technology in Computer Science (IJETTCS) Volume 4, Issue 1, JanuaryFebruary 2015 ISSN 2278-6856 Volume 4, Issue 1, January - February 2015

[4] Habibur Rahman, Dr. Md. Fayzur Rahman, Harun-Or-Rashid ,Stability Improvement of Power System By Using SVC With PID Controller. International Journal ofEmerging Technology and Advanced Engineering Website: www.ijetae.com (ISSN 2250-2459, Volume 2, Issue 7, July 2012).

[5] Imran Azim,Habibur Rahman ,PowerSystem Stability Enhancement by Enhancing the Performance of SVC. International Journal of Science, Engineering \& Technology Research (IJSETR) Volume 2, Issue 3, March- 2013 ISSN: $2278-7798$.

[6] A.Kazemi and M.V.Sohrforouzani, Power system damping using Fuzzy controlled FACTS Devices, International conference on Power system Technology, POWERCON 2004, Singapore.

[7] Bao-Gang, H., Mann, G.K.I. \& Gosine, R.G. A systematic study of fuzzy PID controllers function based evaluation approach, IEEE Trans. On Fuzzy Systems, Vol. 9, Issue 5, Oct. 2001, p. 699.

[8] Suraj Kumar, Priyajit Dash "A Study on TSCS, SSSC, SVC Facts Device", International Journal of Advanced Research in Electrical, Electronics andInstrumentation Engineering(An ISO 3297: 2007 Certified Organization) Vol. 5, Issue 6, June 2016

[9] Li Wang Yuan, Yih Hsu, Damping Of Subsynchronous Resonance UsingExcitation Controllers And Static Var Compensators: A Comparative StudyMember Department of Electrical Engineering, National Taiwan University ,Taipei,Taiwan ,in IEEE Transactions on Energy Conversion, Vol. 3, No. 1, March 1988.
[10] A.E. Hammad and M. El-Sadek. "Application of a thyristor controlled VAR Compensator for damping subsynchronous oscillations in power systems", IEEE Trans. PAS, Vol. 103, IEEE Committee Report, 1987.

[11] D. Z. Fang, Yang Xiao dong; T. S. Chung and K. P.Wong, Adaptive fuzzy-logic SVC damping controller using strategy of oscillation energy descent, IEEE Trans. on Power Systems, Vol.19(3) , Aug. 2004, pp.1414-1421.

\section{BOOKS}

[12] Hingorani and N.G.Gyungi,Understansing FACTS Devices( IEEE Press, 2000)

[13] Prabha Kundur, Power system stability and control.(Tata-McGraw-Hill,1994)

[14] K. R. Padiyar, HVDC Power Transmission systems (2nd edition, new age international publishers.)

[15] Timothy J. Ross, Fuzzy logic with engineering applications (John Wiley \& Sons, Ltd.)

[16] M. Noroozian ,ABB Power Systems, SVC Modelling( Reactive Power Compensation Division, Vāssteras, Sweden, Information NR 500-026E , April 2001) 